\title{
E-business Capabilities in Developed and Developing Countries: Different or the Same?
}

\author{
D. Adebanjo ${ }^{1}$, M. Tickle ${ }^{2}$, Y. Lin ${ }^{1}$, M. Bourlakis ${ }^{3}$ \\ ${ }^{1}$ Business School, University of Greenwich, London, United Kingdom \\ ${ }^{2}$ Management School, University of Liverpool, Liverpool, United Kingdom \\ ${ }^{3}$ School of Management, Cranfield University, United Kingdom \\ ad48@gre.ac.uk
}

\begin{abstract}
This paper compares the e-business capabilities in developed and developing countries; in particular the awareness and usage of e-business tools and the barriers / drivers of adoption. We surveyed 136 managers of organizations (in both developed and developing countries) and analyzed the responses via the SPSS Statistics software package. A number of statistically significant differences were found between the 2 sets of organization; interestingly, however, a number of areas showed minimal difference between the 2 sets of organizations, suggesting the gap between them beginning to close.
\end{abstract}

Keywords - e-business, developed vs. developing countries, operations managers

\section{INTRODUCTION}

This paper studies the use of e-business tools as well as the drivers and barriers to their adoption across both developed and developing countries to investigate differences between the 2 sets of countries. E-business adoption has moved from a 'nice to have' to a necessity due to the vital role it plays in global businesses [1, 2], with many suggesting that the question is not whether or not e-business tools should be adopted but how this adoption should be conducted [3, 4]. E-business tools offer a large array of benefits to those that implement them; examples include increased competitive advantage, improved communication, improved agility, increases in efficiency and access to new markets [5, 6]. Similar benefits of adoption include reduced costs and increased process improvements $[7,8]$ as well as improvements in inventory management, distribution and production planning $[9,10]$.

In recent years there has been an increased interest in the role that e-business plays in the field of operations and supply chain management $[11,12]$; it is for this reason that this paper investigates e-business tools from an operations management perspective. Much has been written about the benefits of e-business tool adoption, however there are a vast array of different tools available to organizations [7] and as such there is currently limited understanding on which tools are used most often and which are the most effective. Similarly, there has been limited research on e-business tool adoption outside of developed countries such as those in Europe, North America and Japan [1]. Those studies that have looked at the diffusion of e-business tools have concluded that developing countries lack the levels of e-business implementation present in developed countries [1, 13]. There has, however, not been a single study confirming these supposed differences. All of these factors serve as motivations for conducting this study.

\section{A. The e-business tools}

As this study investigates e-business tools from an operations management perspective, the authors set about reviewing the literature on this and classified the main activities of operations management into 4 main categories; material management (MM), order tracking and delivery (OTD), storage and retrieval (SR) and supply chain coordination (SCC). The next step was to identify the most prevalent tools within each of these categories; in total, we found 15 prevalent e-business tools across the 4 categories and these are listed in Table I.

TABLE I

E-BUSINESS TOOLS AND THEIR ASSOCIATED CATEGORIES

\begin{tabular}{lll}
\multicolumn{1}{c}{ Category } & & \multicolumn{1}{c}{ Associated Tools } \\
\hline Material & $\bullet$ & E-procurement \\
Management (MM) & $\bullet$ & Demand Forecasting Software \\
\hline & $\bullet$ & GPS \\
Order Tracking and & $\bullet$ & Barcode \\
Delivery (OTD) & $\bullet$ & Radio Frequency Identification \\
& & (RFID) \\
& $\bullet$ & QR Code \\
\hline Storage and Retrieval & $\bullet$ & Automated Storage and Retrieval \\
(SR) & & System \\
& $\bullet$ & Warehouse Management System \\
\hline & $\bullet$ & EDI \\
& $\bullet$ & E-commerce \\
& $\bullet$ & E-Auction \\
Supply Chain & $\bullet$ & Enterprise Resource Planning \\
Coordination (SCC) & (ERP) \\
& $\bullet$ & Customer Relationship \\
& & Management (CRM) \\
& $\bullet$ & Teleconference Systems \\
& $\bullet$ & Project Management Software \\
\hline
\end{tabular}

Upon searching for these 15 tools, the authors discovered that each of the tools are normally used in different areas of the business, with some being versatile 
enough to be usable across multiple business areas. As an example, RFID could be used for logistics, inventory, customer service and production purposes [14]. As such we identified 14 areas of business where e-business tools could be utilized; these include inventory, logistics, quality, capacity, performance measurement, production, customer relations, supplier relations, sales, procurement forecasting, design, people management, and facilities management.

\section{B. Drivers for adopting e-business tools}

Despite the aforementioned benefits organizations are likely to achieve once adopting e-business tools, adoption is not necessarily an easy task; many studies have shown that e-business adoption forces organizations to change the way they operate $[12,15]$. As a result, there have been numerous studies investigating the drivers that encourage organizations to adopt these tools; some such drivers include the availability of in-house skills and knowledge [15] as well as organizational and financial readiness, and pressure from competitors and supply chain partners [16]. Upon reviewing the literature, the authors of this study identified 10 drivers of e-business tool adoption, with these being categorized as either internal or external. These are shown in Table II.

\section{TABLE II}

DRIVERS FOR ADOPTING E-BUSINESS TOOLS

\begin{tabular}{llll}
\hline Internal Drivers & \multicolumn{2}{l}{ External Drivers } \\
\hline - & Improve Competitiveness & $\bullet$ & Improved Integration \\
- & Improve External & $\bullet$ & Pressure from \\
& Relationships & & Competitors \\
• & Frustration with Current & $\bullet$ & Suppliers want us to use \\
& System & & it \\
- & Cost Savings & $\bullet$ & Customers want us to use \\
- Improved Responsiveness & & it \\
& $\bullet$ & Improved Collaboration \\
\hline
\end{tabular}

It is important to note that drivers are likely to differ between countries and especially between regions. Institutional theory is useful in this regard as it suggests that there are 3 forces of pressure that encourage organizations to adopt certain initiatives. These 3 pressures are normative, mimetic and coercive [17, 18]; normative forces are forces placed by the market and are generally as a result of customer pressure, mimetic forces are pressures from competitors who have already successfully adopted such initiatives, and coercive pressures are those imposed by regulatory bodies that attempt to coerce organizations to adopt certain initiatives [19]. Coercive forces are likely to have less of an impact on e-business tool adoption when compared to normative and mimetic forces, especially given that the impact of normative pressures on e-business tool adoption has been studied extensively in recent years [14, 20, 21].

C. Barriers to adopting e-business tools

Alongside the drivers for adoption, there are numerous barriers that stand to impede the success of any e-business tool implementation initiative. Technological barriers include a lack of awareness of the tools and the benefits they can offer [22-24], whereas the cost of adopting a new technology (in terms of implementation, training and maintenance) can also act as a significant barrier [25-27]. A final set of barriers includes the skills present within the organization; a lack of in-house capabilities is an obvious barrier to adoption [24, 26], and there can also be employee resistance (especially if the tool is seen as a threat to employee's jobs) [28, 29]. A lack of sufficient training [23] and a lack of top management commitment [30] can also have a negative impact on the adoption of these tools.

\section{METHODOLOGY}

As the study required responses from participants geographically dispersed, a survey approach was utilized. This approach has been suggested by a number of scholars [31, 32] especially in the field of e-business tool adoption [33-35]. The survey was sent to over 600 managers in over 40 countries and was made available online. In total 136 responses were received and the responses were analyzed via the SPSS Statistics software package.

The survey asked respondents about their awareness, level of usage and perceived effectiveness of the most popular 15 e-business tools (identified via the extensive literature search) as well as the drivers and barriers associated with adopting each of the tools.

In order to categorize each respondent as either "developing" or "developed", the authors used the guidelines of the International Monetary Fund [36] who classify countries as either developed or developing based on their economic development (which includes factors such as their GDP).

\section{RESULTS}

This section details the results of the study and is split into the 3 subcategories of Usage of e-business tools, drivers for adopting e-business tools, and barriers to adopting e-business tools.

\section{A. Usage of e-business tools}

In terms of the e-business tools used, ERP, EDI and teleconferencing systems were the tools most used across both sets of countries, while QR codes, e-auctions, Automated Storage and Retrieval Systems and RFID were the least used. Surprisingly, only 2 of the 15 tools showed statistically significant differences between those in developed and those in developing countries; these were Barcode ( $p=0.001)$ and Automated Storage and Retrieval Systems $(p=0.005)$.

Across both sets of countries the results showed that MM tools are used mainly in the areas of forecasting / demand management, inventory management, logistics, and procurement across both sets of countries; conversely they are used far less in the areas of customer relations, design, and facilities management. OTD tools 
are often used in procurement, inventory management, logistics, and customer relations but are less likely to be used in people management, facilities management, design, and forecasting / demand management. SR tools are mainly used for logistics, capacity, inventory management and facilities management, but are less likely to be used for sales and marketing, design, and customer relations. Finally, SCC tools are used across all business areas, with supplier relations, customer relations, people management and logistics showing the top levels of usage.

In terms of differences between the 2 sets of countries, the results showed a number of statistically significant differences between the 2 sets of countries. For MM tools, differences were found in the business areas of quality management $(\mathrm{p}=0.019)$, procurement $(\mathrm{p}=$ $0.009)$, inventory management $(p=0.003)$, customer relations $(p=0.044)$, supplier relations $(p=0.014)$, and people management $(p=0.049)$; in all cases, developing countries were more likely to use the MM tools in these business areas. Interestingly, for OTD tools, no statistically significant differences were found between the 2 sets of countries in terms of the business areas in which these tools were used. For SR tools, differences were discovered in the areas of performance management $(p=0.028)$, capacity management $(p=$ $0.019)$, people management $(p=0.047)$, and facilities management ( $p=0.010)$; again, developing countries were more likely to use these tools in these business areas in all cases. Finally, for SCC tools, only people management $(p=0.044)$ shows a difference between the 2 sets of countries; once again, developing countries were more likely to use these tools in this business area when compared to their developed counterparts.

\section{B. Drivers for adopting e-business tools}

Respondents were asked to identify the drivers for adopting the various e-business tools from the list of drivers present in Table II (shown earlier).

For MM tools, statistically significant differences were found for all but one external driver, with developing countries citing these drivers more often than their developed counterparts: improved integration $(\mathrm{p}=$ $0.014)$, pressure from competitors $(p=0.001)$, suppliers want us to use it ( $p=0.002)$, and customers want us to use it ( $p=0.012)$. Interestingly, there were no statistically significant differences between the 2 sets of countries for internal drivers; this suggests that normative and mimetic forces play a significant role in the decision to adopt MM tools in developing countries but have a far less significant role in developed countries.

For OTD tools, although developing countries were more susceptible to a greater number of drivers to adopt these tools, only one driver showed a statistically significant result: frustration with current system ( $\mathrm{p}=$ 0.040).

Similarly, for SR tools, only one driver showed a statistically significant result between the 2 sets of countries: customers want us to use it ( $p=0.049$ ).
Interestingly, there were no statistically significant differences for SCC tools; this indicates that for these tools normative forces are less important factors in their adoption, whereas mimetic forces do not play any sort of role in the adoption decision.

\section{Barriers to adopting e-business tools}

Respondents were also asked to identify the various barriers to adopting the e-business tools. For MM tools, the 2 most cited barriers were lack of technical skills and lack of understanding or awareness of the tool. Statistically significant differences were found for lack of training $(\mathrm{p}=0.038)$, insufficient in-house knowledge / skills $(p=0.019)$ and employee resistance to change ( $p$ $=0.018$ ), with developing countries being far more likely to face these barriers.

For OTD tools, the 2 most cited barriers were again lack of technical skills and lack of understanding or awareness of the tool. For these tools, only 2 barriers showed statistically significant differences between the 2 sets of countries: lack of top management support $(\mathrm{p}=$ $0.025)$ and employee resistance to tool $(p=0.018)$. In both cases, developing countries were more likely to encounter these barriers.

In terms of SR tools, the most cited barriers include lack of understanding or awareness of the tool and insufficient in-house knowledge / skills. Four barriers showed statistically significant differences and in all cases developing countries were more likely to encounter these specific barriers: employee resistance to the tool ( $p=$ $0.003)$, insufficient in-house knowledge / skills ( $\mathrm{p}=$ $0.007)$, lack of training $(p=0.012)$, and lack of top management support $(\mathrm{p}=0.001)$.

Finally, the most cited barriers for SCC tools include lack of technical skills, insufficient in-house knowledge / skills and prohibitive costs. Interestingly, however, none of the barriers showed statistically significant differences between the 2 sets of countries.

\section{DISCUSSION}

This study has identified a number of interesting findings; this section will concentrate on discussing the findings in terms of the usage of e-business tools, the drivers for adopting e-business tools and the barriers to adopting e-business tools.

\section{A. Usage of e-business tools}

This paper indicates that MM tools show the most substantial differences between organizations in developing and developed countries, with developing countries far more likely to use these approaches across multiple areas of their business. This suggests that organizations in developing countries are significantly more susceptible to normative and mimetic forces and are therefore under increased pressure to adopt these tools.

For OTD and SCC tools there was only one statistically significant difference; this implies that these 
tools are used equally by both sets of organization, potentially suggesting that developing countries have already closed the gap on their developed counterparts with respect to the usage of these e-business tools. Several previous studies [1, 16, 37] proposed that the adoption of e-business tools is not uniform across all regions and countries; however this study indicates that there is some amount of uniformity with regard to these particular tools.

Finally, those in developing countries are more likely to use SR tools across nearly all business areas when compared to their counterparts in developed countries. This finding makes sense for two reasons; firstly, organizations in developing countries tend to lack resources (both human and physical) and as such areas such as performance management, capacity management and facilities management become a priority in order for them to successfully compete. Secondly, previous studies have shown how developing countries have lagged behind their developed counterparts in these areas for years [38], further suggesting that these areas are now a major concern for organizations based there.

In summary, the results show that organizations in developing countries are more likely to use the vast majority of the e-business tools identified in this study and are also significantly more likely to use them across several areas of their business. In particular, e-business tools for capacity management and facilities management seem to show an increased importance for organizations in developing countries. This result contradicts that of previous studies [13] which suggested that organizations in developed countries had a much higher utilization of all e-business tools. The results of this study also suggest that with regard to $\mathrm{MM}$ and SR tools, organizations in developing countries are more likely to be rapidly adopting such tools, possibly due to the increased pressures they face in terms of external threats as well as internal drivers for efficiency.

\section{B. Drivers for adopting e-business tools}

In terms of drivers, the results for MM tools suggested that normative and mimetic pressures are stronger on organizations in developing countries; this agrees with the findings of some previous studies [39] and suggests that both competitors and partners across the supply chain are able to pressurize these organizations to implement particular tools to suit their individual goals and needs. The increased focus on MM tools by organizations in developing countries could also be down to the geographical distance between themselves and their customers, whereby there is an increased need to ensure product availability and reduce shortages. Internal drivers of reduced cost and increased efficiency were also cited highly by those in both sets of countries, suggesting that the desire to improve current operations is not limited to developed or developing countries.

For OTD and SR tools, only a few tools showed instances where normative and mimetic pressures for adoption are higher in developing countries. Similarly, there were virtually no differences in terms of drivers for
SCC tool adoption between the 2 sets of countries. We believe this is a result of all organizations wishing to be more efficient and competitive as opposed to being pressured by normative and mimetic forces.

In summary, this paper has indicated that drivers for adopting e-business tools vary drastically and are highly dependent on the purpose of the tool as well as the location in which the organization is based. While some studies have shown that e-business tool adoption in developed countries is impacted significantly by normative and mimetic pressures [40, 41], this paper suggests that these pressures differ per individual tool.

\section{Barriers to adopting e-business tools}

The paper has found that those in developed countries are confronted with far fewer barriers to adopting all the e-business tools identified in this study.

MM tools highlighted significant differences in terms of a lack of training and insufficient in-house experience / skills. Interestingly, however, the results for MM tools (as well as SCC tools) showed no difference with respect to top management support; a possible explanation for this would be the earlier finding that suggested partners within the supply chain affirm pressure to adopt these tools, thereby increasing top management's commitment to them. Inversely, SR tools showed significant differences between the 2 sets of countries for top management support; this contrasts with previous studies [27, 39, 42] that did not find top management support to be a significant barrier to e-business tool adoption in developing countries. OTD tools showed significant differences in terms of top management support and employee resistance to change but no differences were found for lack of in-house knowledge / skills or lack of training; this could be explained due to the ease of use of some of these tools (e.g. RFID, barcode) which may reduce the amount of training required in order to adopt them. Interestingly, SCC tools showed no statistically significant differences between the 2 types of organization in terms of barriers, drivers and business areas they are used in; this strongly suggests that these tools are universally accepted across both types of organization.

In general, apart from the SCC tools (which seem to be universally accepted), the results show that employees of organizations in developing countries are significantly more resistant to adoption, even though market forces drive their adoption. On a similar note, if market forces do not encourage the adoption of a particular tool, top management support in developing countries is likely to be significantly less; this all suggests that a significant cultural difference exists between the 2 sets of countries when it comes to adopting e-business tools. Finally, there appears to be a significant difference between the 2 sets of countries in terms of the skills available for adopting the more specialized approaches.

\section{CONCLUSION}


This paper has shown a number of statistically significant differences exist between developing and developed countries in terms of e-business tool usage, the drivers for adopting such tools and the barriers to adoption of these tools.

It has also found that organizations in developed countries did not outperform their developing counterparts in terms of implementation of the e-business tools. This is contrary to previous studies that found developing countries to be lagging behind their developed counterparts $[1,13,37]$; this shows that the high rate of ebusiness tool adoption by developing countries over recent years has allowed developing countries to reduce the perceived gap between the 2 sets of countries.

There are several implications generated by this research; in terms of practical implications, the study has shown that managers in developing countries should be aware that they may face employee resistance when attempting to adopt e-business tools and may also face limited top management support. On the other hand, managers should also expect various pressures to adopt particular e-business tools, not only from their supply chain partners and customers but also from their competitors who are already implementing these tools. In terms of theoretical implications, the differences identified here should be further investigated to understand why certain tools show differences between the 2 sets of countries and others do not. Similarly, the cultural differences between the two sets of countries that may impact on the adoption decision should also be further investigated. Emerging e-business tools such as cloud computing and 3D printing would also be interesting to compare, as these new tools have the potential to quickly change business models and give those in developing countries an early advantage over their developed counterparts.

\section{REFERENCES}

[1] M. Yasin and U. Yavas, "An analysis of Ebusiness practices in the Arab culture," Cross Cultural Management: An International Journal, vol. 14, pp. 68-73, 2007.

[2] E. Ng, "An empirical framework developed for selecting B2B e-business models: the cse of Australian agribusiness firms," Journal of Business \& Industrial Marketing, vol. 20, pp. 218-225, 2005.

[3] M. Porter, "Strategy and the Internet," Harvard Business Review, vol. 79, pp. 63-78, 2001.

[4] R. Voola, J. Carlson, H. Wong, and J. Li, "Resource-based model of e-business adoption in China: an empirical investigation," Journal of Technology Management in China, vol. 5, pp. 227-244, 2010.

[5] M. Sigala, "The information and communication technologies productivity impact on the UK hotel sector," International Journal of
Operations and Production Management, vol. 23, pp. 1224-1245, 2003.

[6] E. Martinez-Caro and J. Cegarra-Navarro, "The impact of e-business on capital productivity," International Journal of Operations and Production Management, vol. 30, pp. 488-507, 2010.

[7] F. Caniato, R. Cagliano, M. Kalchschmidt, R. Golini, and G. Spina, "Evolutionary patterns in e-business strategy," International Journal of Operations and Production Management, vol. 29, pp. 921-945, 2009.

[8] S. Devaraj, L. Krajewski, and J. Wei, "Impact of eBusiness technologies on operational performance: The role of production information integration in the supply chain," Journal of Operations Management, vol. 25, pp. 11991216, 2007.

[9] N. Sanders, "Pattern of information technology use: the impact of buyer-supplier coordination and performance," Journal of Operations Management, vol. 26, pp. 349-367, 2008.

[10] F. Wiengarten, P. Humphreys, A. McKittrick, and B. Fynes, "Investigating the impact of ebusiness applications on supply chain collaboration in the German automotive industry," International Journal of Operations and Production Management, vol. 33, pp. 25-48, 2013.

[11] S. Dong, S. Xu, and K. Zhu, "Information technology in supply chains: the vlue of ITenabled resources under competition," Information Systems Research, vol. 20, pp. 1832, 2009.

[12] F. Wiengarten, B. Fynes, P. Humphreys, R. Chavez, and A. McKittrick, "Assessing the value creation process of e-business along the supply chain," Supply Chain Management: An International Journal, vol. 16, pp. 207-219, 2011.

[13] M. Salwani, G. Marthandan, M. Norzaidi, and S. Chong, "E-commerce usage and business performance in the Malaysian tourism sector: empirical analysis," Information Management \& Computer Security, vol. 17, pp. 166-185, 2009.

[14] T. Laosirihongthong, P. Punnakitikashem, and D. Adebanjo, "Improving supply chain operations by adopting RFID: Evaluation and comparison of enabling factors," Production Planning \& Control, vol. 24, pp. 90-109, 2013.

[15] V. Bardonaba-Juste, L. Lucia-Palacios, and Y. Polo-Redondo, "Antecedents and consequence of e-business adoption for European retailers," Internet Research, vol. 22, pp. 532-550, 2012.

[16] V. Saprikis and M. Vlachopoulou, "Determinants of the use of B2B e-marketplaces," Industrial Management and Data Systems, vol. 112, pp. 619-643, 2012. 
[17] P. J. DiMaggio and W. Powell, "The iron cage revisited: institutional isomorphism and collective rationality in organizational fields," American Sociological Review, vol. 48, pp. 147160, 1983.

[18] R. Scott, Institutions and Organizations. Thousand Oaks, CA: Sage, 1995.

[19] Q. Zhu and J. Sarkis, "The moderating effects of institutional pressures on emergent green supply chain practices and performance," International Journal of Production Research, vol. 45, pp. 4333-4355, 2007.

[20] R. Spekman and P. Sweeney, "RFID: from concept to implementation," International Journal of Physical Distribution and Logistics Management, vol. 36, pp. 736-754, 2006.

[21] M. Attaran, "RFID: an enabler of supply chain operations," Supply Chain Management: An International Journal, vol. 12, pp. 249-257, 2007.

[22] Y. Duan, A. Mullins, D. Hamblin, S. Stanek, H. Sroka, V. Machado, et al., "Addressing ICTs skill challenges in SMEs: insights from three country investigations," Journal of European Industrial Training, vol. 26, pp. 430-441, 2002.

[23] E. Loukis, D. Spinellis, and A. Katsigiannis, "Barriers to the Adoption of B2B e-Marketplaces by Large Enterprises: Lessons Learned From the Hellenic Aerospace Industry," Information Systems Management, vol. 28, pp. 130-146, 2011.

[24] K. Tan, S. Chong, B. Lin, and U. Eze, "Internetbased ICT adoption among SMEs: Demographic versus benefits, barriers, and adoption intention," Journal of Enterprise Information Management, vol. 23, pp. 27-55, 2010.

[25] Y. Barlette and V. Fomin, "Exploring the Suitability of IS Security Management Standards for SMEs," presented at the Proceedings of the 41st Hawaii International Conference on System Sciences (HICSS), Hawaii, 2008.

[26] M. Beckinsale, M. Ram, and N. Theodorakopoulos, "ICT adoption and ebusiness development: Understanding ICT adoption amongst ethnic minority businesses," International Small Business Journal, vol. 29, pp. 193-219, 2010.

[27] A. Khatibi, V. Thyagarajan, and A. Seetharaman, "E-commerce in Malaysia: Perceived Benefits and Barriers," Interfaces, vol. 28, pp. 77-82, 2003.

[28] F. Caniato, A. Longoni, and A. Moretto, "Effective eProcurement implementation process," Production Planning \& Control, vol. 23, pp. 935-949, 2012.

[29] A. Scupola, "The adoption of internet commerce by SMEs in the south of Italy: an environmental, technological and organizational perspective,"
Journal of Global Information Technology Management, vol. 6, pp. 51-71, 2003.

[30] D. Adebanjo and T. Laosirihongthong, "Adoption of web-based order-processing systems: experiences from tier-1 suppliers in the automotive supply chain," Production Planning \& Control, vol. 25, pp. 1287-1301, 2013.

[31] D. Delgado-Hernandez and E. Aspinwall, "Improvement tools in the UK construction industry," Construction Management and Economics, vol. 23, pp. 965-977, 2005.

[32] B. Adenso-Diaz, P. Gonzalez-Torre, and V. Garcia, "A capacity management model in service industries," International Journal of Service Industry Management, vol. 13, pp. 286302, 2002.

[33] P. Johnson, R. Klassen, M. Leenders, and A. Awaysheh, "Utilizing e-business technologies in supply chains: The impact of firm characteristics and teams," Journal of Operations Management, vol. 25, pp. 1255-1274, 2007.

[34] P. Evangelista, R. Mogre, A. Perego, A. Raspagliesi, and E. Sweeney, "A survey based analysis of IT adoption and 3PLs' performance," Supply Chain Management: An International Journal, vol. 17, pp. 172-186, 2012.

[35] R. Paton, R. Wagner, and R. MacIntosh, "Engineering education and performance: the German machinery and equipment sector," International Journal of Operations \& Production Management, vol. 32, pp. 796-828, 2012.

[36] I. M. Fund, "World Economic Outlook Recovery Strengthens, Remains Uneven," International Monetary Fund, Washington, DC2014.

[37] X. Wong, D. Yen, and X. Fang, "E-Commerce Development in China and its Implication for Business," Asia Pacific Journal of Marketing and Logistics, vol. 16, pp. 68-83, 2004.

[38] C. Kenny, "The internet and economic growth in less-developed countries- A case of managing expectations?," Oxford Development Studies, vol. 31, 2003.

[39] O. Iyanda and S. Ojo, "Motivation, influences, and perceived effect of ICT adoption in Botswana organizations," International Journal of Emerging Markets, vol. 3, pp. 311-322, 2008.

[40] X. Duan, H. Deng, and B. Corbitt, "Evaluating the critical determinants for adopting e-market in Australian small-and-medium sized enterprises," Management Research Review, vol. 35, pp. 289308, 2012.

[41] P. Ifinedo, "Internet/e-business technologies acceptance in Canada's SMEs: an exploratory investigation," Internet Research, vol. 21, pp. 255-281, 2011.

[42] K. Tan, S. Chong, B. Lin, and U. Eze, "Internetbased ICT adoption: evidence from Malaysian 
SMEs," Industrial Management \& Data Systems,

vol. 109, pp. 224 - 244, 2009. 